\title{
Bile salt hydrolase activity and cholesterol assimilation of lactic acid bacteria isolated from flowers
}

\author{
Rattanatda Nuhwa ${ }^{1}$, Somboon Tanasupawat ${ }^{2 *}$, Malai Taweechotipatr ${ }^{3}$, Jaruwan Sitdhipol $^{4}$, Ancharida Savarajara ${ }^{5}$ \\ ${ }^{1}$ Program Biotechnology, Faculty of Science, Chulalongkorn University, Bangkok 10330, Thailand. \\ ${ }^{2}$ Department of Biochemistry and Microbiology, Faculty of Pharmaceutical Sciences, Chulalongkorn University, Bangkok 10330, Thailand. \\ ${ }^{3}$ Department of Microbiology, Faculty of Medicine, Srinakharinwirot University, Bangkok 10110, Thailand. \\ ${ }^{4}$ Biodiversity Research Centre, Thailand Institute of Scientific and Technological Research (TISTR), Pathum Thani 12120, Thailand. \\ ${ }^{5}$ Department of Microbiology, Faculty of Science, Chulalongkorn University, Bangkok 10330, Thailand.
}

\section{ARTICLE INFO \\ Received on: 20/03/2019 \\ Accepted on: 09/04/2019 \\ Available online: 05/06/2019}

\section{Key words:}

Bile salt hydrolase,

cholesterol assimilation, lactic acid bacteria.

\begin{abstract}
A total of 16 isolates of lactic acid bacteria (LAB) from flowers were screened for the bile salt hydrolase activity on MRS (de Man, Rogosa and Sharpe; Difco) agar supplemented with $0.5 \%(\mathrm{w} / \mathrm{v})$ taurodeoxycholic acid. The isolates were divided into two groups based on their phenotypic characteristics and 16S rRNA gene sequence analysis of the representative isolates. Group I isolates were cocci as the members of genus Enterococcus. Isolates FM1-1, FM1-2, FM12-1, and FM12-2 were identified as Enterococcus durans (100\% similarity), isolate FM2-3 was identified as Enterococcus gallinarum (99.92\% similarity), while the isolate FM11-2 was identified as Enterococcus lactis (99.77\% similarity). Group II isolates were rods as the members of genus Lactobacillus. They were identified as Lactobacillus plantarum subsp. plantarum (the representative isolates, FM3-1 and FM16-2, showed 100\% similarity). Eleven isolates, including FM1-1, FM1-2, FM2-3, FM3-1, FM4-2, FM11-2, FM12-1, FM12-2, FM14-1, FM14-2, and FM16-2, exhibited bile salt hydrolase activity. All LAB isolates showed the cholesterol assimilated ability ranged from $9.57 \%$ to $51.69 \%$. The isolate FM11-2 efficiently assimilated the cholesterol with 51.69\%.
\end{abstract}

\section{INTRODUCTION}

Lactic acid bacteria (LAB) are Gram-positive, acid-tolerant, non-sporulating, non-respiring, rod-shaped, or cocci that produce lactic acid as a major end product. Several genera of LAB, especially Lactobacillus, Lactococcus, Leuconostoc, Pediococcus, and Enterococcus involved with cholesterollowering effects in serum could produce bile salt hydrolase (BSH) (Ahn et al., 2003). LAB are isolated from various environments, including intestines, feces, fermented foods, dairy products, flowers, leaves, fruits (Abushelaibi et al., 2017; Itoi et al., 2009; Jarocki et al., 2014; Kawasaki et al., 2011; Kim et al., 2013; Xu et al., 2016), functional food materials, and probiotics

"Corresponding Author

Somboon Tanasupawat, Department of Biochemistry and Microbiology, Faculty of Pharmaceutical Sciences, Chulalongkorn University, Bangkok 10330, Thailand.E-mail: Somboon.T@ chula.ac.th
(Foligne et al., 2013; Solieri et al., 2014). They are used as probiotics, live bacteria that are good for the host health. LAB play a beneficial role as a health promoter on their host. Nowadays, the interested ability of probiotic is BSH producing that has become the focus of attention on account of its influence on cholesterol metabolism. The bile salt hydrolase activity of probiotic bacterium residing in the gastrointestinal tract has often being associated with its cholesterol lowering effects. The aim of this study was to isolate and identify LAB obtained from the plant sources for the screening of their BSH activity and cholesterol assimilation.

\section{MATERIALS AND METHODS}

\section{Sources and isolation}

Eigth flower samples were collected from Nakhon $\mathrm{Si}$ Thammarat and Bangkok, Thailand (Table 1) and were kept in $4^{\circ} \mathrm{C}$ until the isolation. Approximately, $1 \mathrm{~g}$ of sample was inoculated in MRS under anaerobic conditions at $37^{\circ} \mathrm{C}$ for $48-72$ hours (Prasirtsak et al., 2013). The aliquot was streaked on MRS agar plate containing 
Table 1. Source, location and identification based on 16S rRNA sequence of isolates.

\begin{tabular}{lllll}
\hline Flower of & Isolate no. & Province & Group & Identification \\
\hline $\begin{array}{l}\text { Gardenia jasminoides } \\
\text { Hibiscus syriacus }\end{array}$ & FM1-1, FM1-2 & Nakhon Si Thammarat & I & E. durans \\
Ixora lucida & FM12-1, FM12-2 & Nakhon Si Thammarat & I & E. durans \\
Solanum torvum & FM2-3 & Nakhon Si Thammarat & I & E. gallinarum \\
& FM11-2 & Nakhon Si Thammarat & I & E. lactis \\
Wrightia religiosa & FM11-1, FM11-3 & & I & Enterococcus sp. \\
& FM3-1, & Nakhon Si Thammarat & II & Llantarum \\
Leucaena leucocephala & FM4-1, FM4-2 & & I & Enterococcus sp. \\
Jatropha podagrica & FM13-1 & Nakhon Si Thammarat & II & L. plantarum \\
Tabernaemontana divaricata & FM16-1, FM16-2 & Bangkok & II & L. plantarum
\end{tabular}

$0.3 \% \mathrm{CaCO}_{3} 37^{\circ} \mathrm{C}$ for 48 hours. The single colony of $\mathrm{LAB}$, clear zone colony, was picked up and further purified on MRS agar plates at $37^{\circ} \mathrm{C}$ for 48 hours

\section{Identification methods}

\section{Phenotypic characterization}

The cells cultivated on MRS agar plate containing $0.3 \%$ $\mathrm{CaCO}_{3}$ after incubated at $37^{\circ} \mathrm{C}$ for 48 hours were determined for Gram staining, cell morphology, and catalase activity. Phenotypic characteristics, including aesculin hydrolysis, nitrate reduction, arginine hydrolysis, growth in $0 \%, 4 \%, 6 \%$, and $8 \%(\mathrm{w} / \mathrm{v}) \mathrm{NaCl}$ concentrations, and growth at the temperature $15^{\circ} \mathrm{C}, 30^{\circ} \mathrm{C}, 37^{\circ} \mathrm{C}$, and $45^{\circ} \mathrm{C}$ and at $\mathrm{pH} 2.0,4.0$, and 9.0, and acid formation on various carbon sources, were determined as previously described (Tanasupawat et al., 1998). Hierarchical cluster analysis was conducted by using SPSS for Windows version 22.0 based on the phenotypic characteristics of the isolates.

\section{Genotypic characterization}

16S rRNA gene of each represented groups was amplified using polymerase chain reaction (PCR) with two primers as 20F (5'-AGTTTGATCCTGGCTC-3') and 1530R (5'-AAGGAGGTGATCC AGCC-3'). Agarose gel electrophoresis was performed to validate the quality of PCR fragments. The purified PCR products were sequenced with the primers 27F (5'-AGAGTTTGATCMTGGCTCAG-3') and 1492R (5'-TACGGYTACCTTGTTACGACTT-3'). The amplified 16S rRNA gene sequence was analyzed by Macrogen, Korea. The almost-complete 16S rRNA gene sequence was obtained and was aligned manually against the sequences which were obtained from the GenBank/EMBL/DDBJ database using BioEdit software (Ibis Biosciences). The sequences of strains were aligned with the selected sequences obtained from GenBank using CLUSTAL_W algorithm (Clustal et al., 1994). The values for sequence similarity among the closest strains were analyzed using the EzTaxon-e server (Kim et al., 2012). The alignment was edited manually to remove gaps and ambiguous nucleotides before the construction of phylogenetic trees. The confidence values of individual branches in the neighborjoining phylogenetic tree were reconstructed using MEGA version 7.0 (Kumar et al., 2016; Saitou and Nei, 1987). Topologies of phylogenetic trees were evaluated via bootstrap analysis based on 1,000 replicates (Felsenstein, 1985).

\section{Screening of acid and bile tolerance}

Acid and bile tolerance were performed according to a modification of the previously described method (Thamacharoensuk et al., 2013). Briefly, $10^{8} \mathrm{CFU} / \mathrm{ml}$ of each LAB culture was inoculated into MRS broth adjusting to $\mathrm{pH} 2$ for acid tolerance and containing $0.3 \%$ bile salt for bile tolerance, and then incubated at $37^{\circ} \mathrm{C}$. Cell viability was screened on MRS agar plate using the dropping on MRS plate at 0 and 3 hours in duplicate. Lactobacillus rhamnosus LMG $18243^{\mathrm{T}}$ (strain Gorbach-Goldin, GG) was a positive control.

\section{Screening of bile salt hydrolase activity}

All LAB strains were tested for bile salt hydrolase activity by qualitative direct plate assay (Ahn et al., 2003; Dashkevicz and Feighner, 1989; Sedláčková et al., 2015). Briefly, $10 \mu 1$ (109 cell/ $\mathrm{ml}$ ) of bacteria cell were spotted on MRS agar plates supplemented with $0.5 \%(\mathrm{w} / \mathrm{v})$ sodium salt of taurodeoxycholic acid (TDCA; Sigma, USA) and $0.37 \mathrm{~g} / 1$ of calcium chloride $\left(\mathrm{CaCl}_{2}\right)$ incubated under anaerobic condition at $37^{\circ} \mathrm{C}$ for $48-72$ hours. MRS agar medium plates without the supplementation of TDCA were used as a negative control. The presence of precipitated bile acid around colonies (called as opaque halo) was considered as a positive reaction. The experiment was performed in triplicate.

\section{Screening of cholesterol assimilation}

All LAB were investigated to assimilate cholesterol in MRS broth containing $100 \mu \mathrm{g} / \mathrm{ml}$ of cholesterol-polyethylene glycol (PEG) 600 (Sigma, India). Each inoculum (1\%, v/v) was added into MRS-cholesterol-PEG 600 and was incubated at $37^{\circ} \mathrm{C}$ for 24 hours. The cholesterol in the spent broths was first extracted by the procedure described by Tomaro-Duchesneau et al. (2014). The total cholesterol content of the evaporated residues was then determined using a protocol modified from the previous experiment (Rudel and Morris, 1973). A standard curve of absorbance related to cholesterol concentrations was generated using the cholesterol concentrations: $0,6.25,12.5,25,50,100$, and $200 \mu \mathrm{g} / \mathrm{ml}$ cholesterol in MRS.

\section{Statistical analysis}

Statistical difference was analyzed by using the one-way analysis of variance (ANOVA) of the Tukey method (SPSS 22.0). A probability of $p$ value $<0.05$ was considered as significant. 


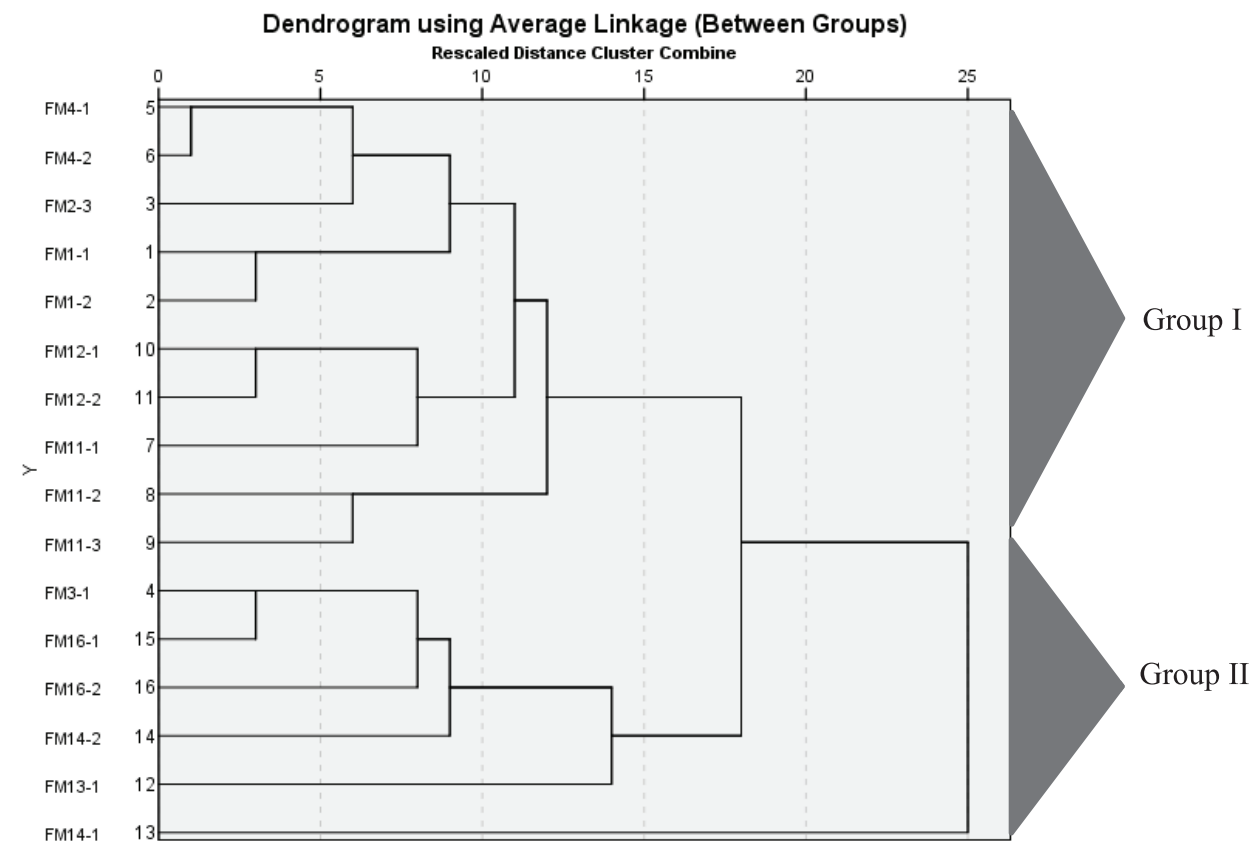

Figure 1. Dendrogram using average linkage (between groups) presenting the hierarchical cluster of LAB isolates based on thephenotypic characteristics.

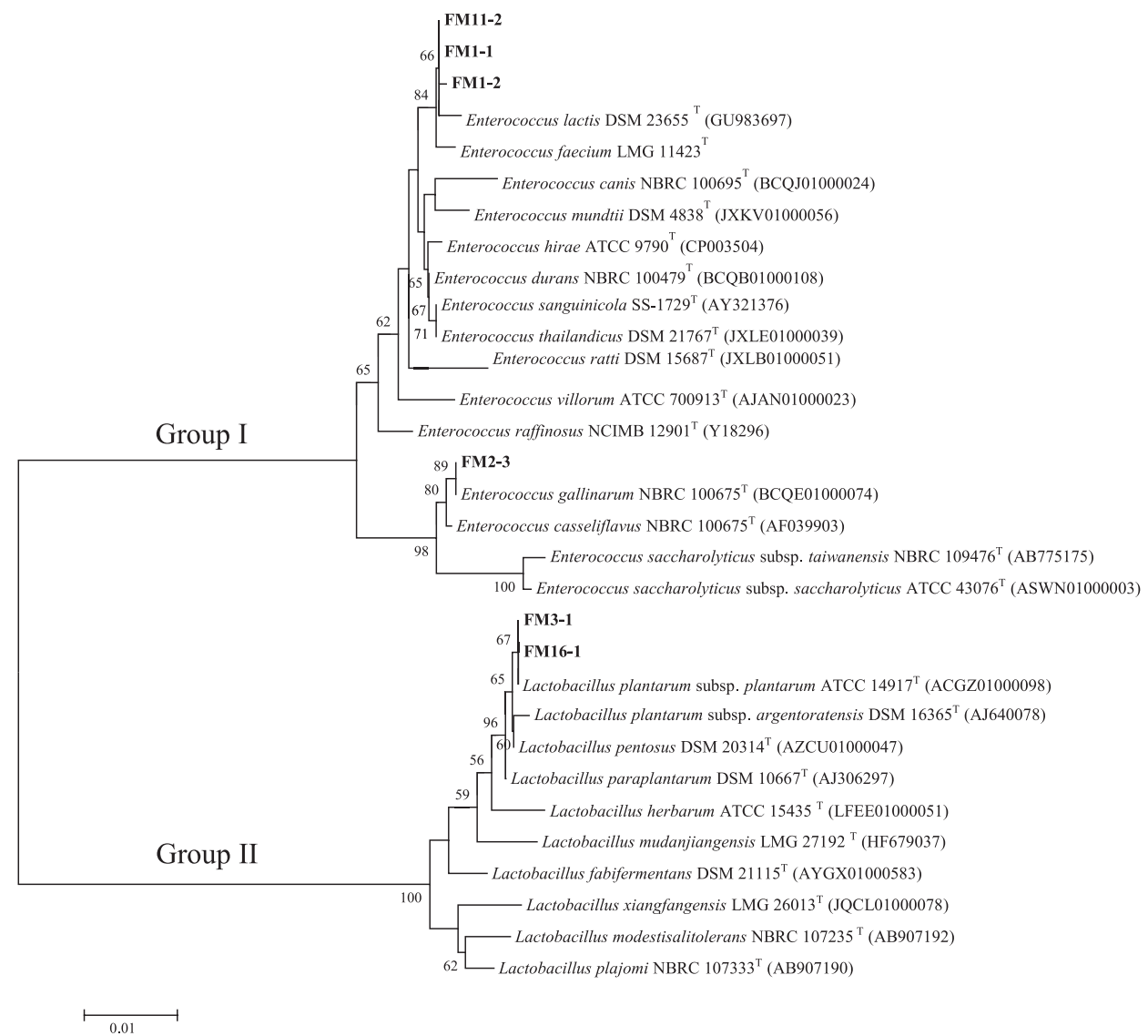

Figure 2. Neighbor-joining tree of the representative isolates based on the 16S rRNA gene sequences. Bootstrap values are showed as percentages of 1,000 replications; only values $>50 \%$ are indicated. Bar 0.01 substitutions per nucleotide position. 
Table 2. Differential phenotypic characteristics of isolates and BSH activity.

\begin{tabular}{lcc}
\hline Characteristics & Group I & Group II \\
\hline No. of isolate & $\mathbf{1 0}$ & $\mathbf{6}$ \\
\hline Growth temp $\left({ }^{\circ} \mathrm{C}\right)$ & $15-45$ & $15-37$ \\
Bile salt tolerance $(0.3 \%)$ & $+(-1)$ & $+(-1)$ \\
Aesculin hydrolysis & - & + \\
Arginine hydrolysis & $-(+3)$ & $+(-2)$ \\
Nitrate reduction & $-(+3)$ & - \\
Acid production from & & \\
D-Galactose & $+(-1)$ & + \\
Sorbitol & $-(+1)$ & $+(-1)$ \\
Sucrose & + & $+(-1)$ \\
D-Xylose & $+(w 2)$ & + \\
& FM1-1, FM1-2, FM2-3, & FM3-1, FM14-2, FM14-1, \\
BSH activity positive & FM4-2, FM11-2, FM12-1, & FM16-2 \\
\hline
\end{tabular}

+ : positive reaction; w: weak reaction; -: negative reaction. Numbers in the parentheses indicate the number of isolates shows positive, weakly and negative reaction.

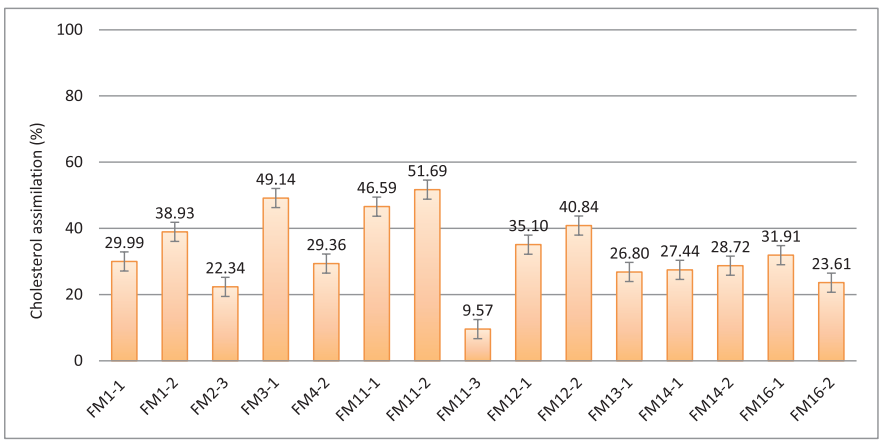

Figure 3. Cholesterol assimilation of isolates in MRS broth supplemented 100 $\mu \mathrm{g} / \mathrm{ml}$ of cholesterol, incubated for 48 hours $(n=3)$. MRS broth supplemented cholesterol without bacterial cells was used as controls. Statistical analysis: ANOVA, Tukey's homogenous subsets generated from pair wise comparison.

\section{RESULTS AND DISCUSSION}

\section{Identification of isolates}

Sixteen LAB strains were isolated from nine flower samples collected from Nakhon Si Thammarat and Bangkok, Thailand (Table 1). All strains were Gram-positive, including 10 cocci (FM1-1, FM1-2, FM2-3, FM4-1, FM4-2, FM11-1, FM112, FM11-3, FM12-1, and FM12-2) and six rod-shaped bacteria (FM3-1, FM13-1, FM14-1, FM14-2, FM16-1, and FM16-2). They were facultative anaerobic and catalase negative. Most of them grew at $\mathrm{pH} 2.0$ and tolerated in $0.3 \%$ bile salt and in $4 \%-8 \%$ $\mathrm{NaCl}$. All did not produce gas from the glucose. They produced acid from L-arabinose, D-cellobiose, D-fructose, glucose, lactose, maltose, D-mannitol, D-mannose, melibiose, rhamnose, ribose, salicin, trehalose, and D-xylose. They were divided into two groups as the members of genus Enterococcus and Lactobacillus based on their phenotypic characteristics and 16S rRNA gene sequence similarity of the representative strains (Figs. 1 and 2). Their variable characteristics are shown in Table 2.

Group I consisted of 10 isolates, which were FM11, FM1-2, FM2-3, FM4-1, FM4-2, FM11-1, FM11-2, FM11-3,
FM12-1, and FM12-2. They were cocci in the genus Enterococcus. The 16S rRNA gene sequence results indicated that FM1-1, FM12, FM12-1, and FM12-2 were closely related to Enterococcus durans NBRC $100479^{\mathrm{T}}(99.71 \%$ and $99.78 \%$ similarity) and were identified as E. durans (Collins et al., 1984). Isolates FM2-3 and FM11-2 showed $99.92 \%$ and $99.78 \%$ similarity to Enterococcus gallinarum NBRC $100675^{\mathrm{T}}$ and Enterococcus lactis BT159 ${ }^{\mathrm{T}}$; therefore, they were identified as E. gallinarum and E. lactis, respectively (Collins et al., 1984; Morandi et al., 1992).

Group II consisted of six isolates, which were FM3-1, FM13-1, FM14-1, FM14-2, FM16-1, and FM16-2. They were rods in the genus Latobacillus. Their variable characteristics are shown in Table 2. The 16S rRNA gene sequence of representative strains in this group (FM3-1 and FM16-1) showed 100\% similarity to Lactobacillus plantarum ATCC $14917^{\mathrm{T}}$, therefore, they were identified as L. plantarum (Bringel et al., 2005).

From these results, LAB isolated from different species of flowers showed unique properties, such as the ability to ferment many kinds of carbohydrates, including fructose that they are considered to have fructophilic properties. Their distribution is correlated with the major carbohydrate sources in a specific habitat (Endo, 2012; Kuda et al., 2016).

\section{Screening of acid and bile tolerance}

LAB isolates could tolerate in the medium at $\mathrm{pH} 2$ except the isolates FM1-2 and FM12-1 in Group I and FM14-2 in Group II, while all isolates could tolerate in the medium containing $0.3 \%$ bile except the isolate FM14-2 in Group I and FM 14-1 in Group II.

\section{Screening of bile salt hydrolase activity}

Enterococcus isolates FM1-1, FM1-2, FM2-3, FM4-2, FM11-2, FM12-1, FM12-2, L. plantarum isolates FM3-1, FM141, FM14-2, and FM16-2 (Table 2) exhibited BSH activity, while E. durans V18 and Leuconostoc mesenteroides V12 and V21 from sichuan kimchi, E. faecium B20, B21 isolated from stinky soybean, Pediococcus ethanolidurans D13 and L. plantarum D24 and D25 from dongbei kimchi and (Xu et al., 2016), Leuc. lactis KC117496 from idli batter (Saravanan et al., 2016), L. plantarum Lp3 from fermented yak milk (Ding et al., 2017), and L. plantarum RC from raw cheese (Shekh et al., 2016) were also reported to have BSH activity.

\section{Screening of cholesterol assimilation}

The isolates exhibited cholesterol assimilation ability ranged from $9.57 \%$ to $51.69 \%$. The isolate E. lactis FM11-2 could efficiently assimilate and showed the highest cholesterol assimilation with $51.69 \%$ (Fig. 3). According to the probiotics, LAB are Generally Recognized as Safe (Rolfe, 2000) are most commonly used because of their significant role in resistance to the disease. Our LAB isolates could exhibit BSH activity that may be useful to reduce serum cholesterol levels in the patient with hypercholesterolemia and also prevent hypercholesterolemia in normal people (Chae et al., 2013). The other probiotic properties of the isolates should be done for further study.

\section{CONCLUSION}

In this study, Enterococcus strains were isolated from the flowers of Gardenia jasminoides, Hibiscus syriacus, Ixora 
lucida, and Solanum torvum; while Lactobacillus strains were from Wrightia religiosa, Leucaena leucocephala, Jatropha podagrica, and Tabernaemontana divaricate. Seven Enterococcus isolates and four L. plantarum isolates exhibited BSH activity. All isolates exhibited cholesterol assimilation, but isolate FM11-2 showed the highest activity that may be useful as probiotics for the reduction of cholesterol levels.

\section{FINANCIAL SUPPORT}

This study was supported by the Grant for International Research Integration: Research Pyramid, Ratchadaphiseksomphot Endowment Fund (GCURP_58_01_33_01), Chulalongkorn University, as well as Chulalongkorn University.

\section{CONFLICT OF INTERESTS}

The authors declare that there are no conflicts of interest.

\section{REFERENCES}

Abushelaibi A, Al-Mahadin S, El-Tarabily K, Shah NP, Ayyash M. Characterization of potential probiotic lactic acid bacteria isolated from camel milk. LWT Food Sci Technol, 2017; 79:316-25.

Ahn YT, Kim GB, Lim KS, Baek YJ, Kim HU. Deconjugation of bile salts by Lactobacillus acidophilus isolates. Int Dairy J, 2003; 13(4):303-11.

Bringel F, Castioni A, Olukoya DK, Felis GE, Torriani S, Dellaglio F. Lactobacillus plantarum subsp. argentoratensis subsp. nov., isolated from vegetable matrices. Int J Syst Evol Microbiol, 2005; 55:1629-34.

Chae JP, Valeriano VD, Kim GB, Kang DK. Molecular cloning, characterization and comparison of bile salt hydrolases from Lactobacillus johnsonii PF 01. J Appl Microbiol, 2013; 114(1):121-33.

Collins MD, Jones D, Farrows JAE, Kilpper-Bälz R, Schleifer KH. Enterococcus avium nom. rev., comb. nov.; E. casseliflavus nom. rev., comb. nov.; E. durans nom. rev., comb. nov.; E. gallinarum comb. nov.; and E. malodoratus sp. nov. Int J Syst Bacteriol, 1984; 34:220-3.

Dashkevicz MP, Feighner SD. Development of a differential medium for bile salt hydrolase-active Lactobacillus spp. J Appl Environ Microbiol, 1989; 55:11-6.

Ding W, Shi C, Chen M, Zhou J, Long R, Guo X. Screening for lactic acid bacteria in traditional fermented Tibetan yak milk and evaluating their probiotic and cholesterol-lowering potentials in rats fed a highcholesterol diet. J Funct Foods, 2017; 32:324-32.

Endo A. Fructophilic lactic acid bacteria inhabit fructose-rich niches in nature. Microb Ecol Health Dis, 2012; 23:18563.

Felsenstein J. Confidence limits on phylogenies: an approach using the bootstrap. Evolution, 1985; 39:783-91.

Foligne B, Daniel C, Pot B. Probiotics from research to market: the possibilities, risks and challenges. Curr Opin Microbiol, 2013; 16:284-92.

Itoi S, Yuasa K, Washio S, Abe T, Ikuno E, Sugita H. Phenotypic variation in Lactococcus lactis subsp. Lactis isolates derived from intestinal tracts of marine and freshwater fish. J Appl Microbiol, 2009; 107:867-74.

Jarocki P, Podleśny M, Glibowski P, Targoński Z. A new insight into the physiological role of bile salt hydrolase among intestinal bacteria from the genus Bifidobacterium. PloS One, 2014; 9(12):e114379.

Kawasaki S, Kurosawa K, Miyawaki M, Yagi C, Kitajima Y, Tanaka S, Irisawa T, Okada S, Sakamoto M, Ohkuma M, Niimura Y. Lactobacillus floricola $\mathrm{sp}$. Nov., lactic acid bacteria isolated from mountain flowers. Int J Syst Evol Microbiol, 2011; 61:1356-9.

Kim EB, Tyler CA, Kopit LM, Marco ML. Draft genome sequence of fructophilic Lactobacillus florum. Genome Announc, 2013; $1: \mathrm{e} 00025-12$

Kim OS, Cho YJ, Lee K, Yoon SH, Kim M, Na H, Park SC, Jeon YS, Lee JH, Yi H, Won S, Chun J. Introducing EzTaxon-e: a prokaryotic 16S rRNA gene sequence database with phylotypes that represent uncultured species. Int J Syst Evol Microbiol, 2012; 62:716-21.
Kuda T, Kataoka M, Nemoto M, Kawahara M, Takahashi H, Kimura, B. Isolation of lactic acid bacteria from plants of the coastal Satoumi regions for use as starter cultures in fermented milk and soymilk production. LWT-Food Sci Technol, 2016; 68:202-207.

Kumar S, Stecher G, Tamura K. MEGA7: molecular evolutionary genetics analysis version 7.0 for bigger datasets. Mol Biol Evol, 2016; 33:1870-4.

Morandi S, Cremonesi P, Povolo M, Brasca M. Enterococcus lactis sp. nov., from Italian raw milk cheeses. Int J Syst Evol Microbiol, 2012; 62:1992-6.

Prasirtsak B, Tanasupawat S, Boonsombat R, Kodama K, Thongchul N. Characterization of lactic acid producing bacteria from Thai sources. J Appl Pharm Sci, 2013; 3:033-8.

Rolfe RD. The role of probiotic cultures in the control of gastrointestinal health. J Nutr, 2000; 130(2):396S-402S.

Rudel LL, Morris MD. Determination of cholesterol using o-phthalaldehyde. J Lipid Res, 1973; 14:364-6.

Saitou N, Nei M. The neighbor-joining method: a new method for reconstructing phylogenetic trees. Mol Biol Evol, 1987; 4:406-25.

Saravanan C, Shetty P, Kumar H. Isolation and characterization of exopolysaccharide from Leuconostoc lactis KC117496 isolated from idli batter. Int J Biol Macromol, 2016; 90:100-6.

Sedláčková $\mathrm{P}$, Horáčková Š, Shi T, Kosová M, Plocková M. Two different methods for screening of bile salt hydrolase activity in Lactobacillus strains. Czech J Food Sci, 2015; 33:13-8.

Shekh SL, Dave JM, Vyas BRM. Characterization of Lactobacillus plantarum strains for functionality, safety and $\gamma$-amino butyric acid production. LWT Food Sci Technol, 2016; 74:234-41.

Solieri L, Bianchi A, Mottolese G, Lemmetti F, Giudici P. Tailoring the probiotic potential of non-starter Lactobacillus strains from ripened Parmigiano Reggiano cheese by in vitro screening and principal component analysis. Food Microbiol, 2014; 38:240-9.

Tanasupawat S, Okada S, Komagata K. Lactic acid bacteria found in fermented fish in Thailand. J Gen Appl Microbiol, 1998; 44(3):193-200.

Thamacharoensuk T, Thongchul N, Taweechotipatr M, Tolieng V, Kodama K, Tanasupawat S. Screening and characterization of lactic acid bacteria from animal faeces for probiotic properties. Thai J Vet Med, 2013; 43(4):541-51.

Clustal W. Thompson JD, Higgins DG, Gibson TJ (eds.). Improving the sensitivity of progressive multiple sequence alignment through sequence weighting, position-specific gap penalties and weight matrix choice. Nucleic Acids Res, 1994; 22:4673-80.

Tomaro-Duchesneau C, Jones ML, Shah D, Jain P, Saha S, Prakash S. Cholesterol assimilation by Lactobacillus probiotic bacteria: an in vitro investigation. BioMed Res Int, 2014;1-9.

Xu S, Liu T, Radji C, Akorede I, Yang J, Chen L. Isolation, identification, and evaluation of new lactic acid bacteria strains with both cellular antioxidant and bile salt hydrolase activities in vitro. J Food Prot, 2016; 79(11):1919-28.

\section{How to cite this article:}

Nuhwa R, Tanasupawat S, Taweechotipatr M, Sitdhipol J, Savarajara A. Bile salt hydrolase activity and cholesterol assimilation of lactic acid bacteria isolated from flowers. J Appl Pharm Sci, 2019; 9(06):106-110. 